This item was submitted to Loughborough's Research Repository by the author.

Items in Figshare are protected by copyright, with all rights reserved, unless otherwise indicated.

\title{
Corrigendum to 'Digital detox: The effect of smartphone abstinence on mood, anxiety, and craving' [Add. Behav. 99 (2019) 106013]
}

\section{PLEASE CITE THE PUBLISHED VERSION}

https://doi.org/10.1016/j.addbeh.2019.106265

\section{PUBLISHER}

Elsevier

\section{VERSION}

AM (Accepted Manuscript)

\section{PUBLISHER STATEMENT}

This paper was accepted for publication in the journal Addictive Behaviors and the definitive published version is available at https://doi.org/10.1016/j.addbeh.2019.106265

\section{LICENCE}

CC BY-NC-ND 4.0

\section{REPOSITORY RECORD}

Wilcockson, Thom, AM Osborne, and DA Ellis. 2020. "Corrigendum to 'digital Detox: The Effect of Smartphone Abstinence on Mood, Anxiety, and Craving' [add. Behav. 99 (2019) 106013]”. Loughborough University. https://hdl.handle.net/2134/13234280.v1. 


\section{Corrigendum}

Corrigendum to 'Digital detox: The effect of smartphone abstinence on mood, anxiety, and craving'

Addictive Behaviors 99 (2019), 106013

Wilcockson T.D.W. ${ }^{\mathrm{a}, \mathrm{b}}$, Osborne A.M. ${ }^{\mathrm{c}}$, Ellis D.A. ${ }^{\mathrm{b}}$

${ }^{a}$ Loughborough University, Loughborough, UK

${ }^{\mathrm{b}}$ Lancaster University, Lancaster, UK

${ }^{\mathrm{c}}$ Duke-NUS Medical School, Singapore

Following publication, the authors became aware of an error that occurred during data entry. Specifically, two columns of data were mislabelled whereby participants craving scores at time 1 were incorrectly labelled as Smartphone Addiction Inventory Scores (SPAI) (and vice versa). Corrected results and figures are provided below. A revised post-print that incorporates all these edits is also available https://doi.org/10.31234/osf.io/c85kx.

Following these changes, the overall results and conclusions remain unchanged. The authors would like to apologise for any inconvenience caused.

\section{$\underline{\text { Introduction }}$}

'The aim of this project is therefore to examine the effect on mood, anxiety, and craving change when participants stop using their smartphone for 24-hours.'

Should read:

'The aim of this project is therefore to consider how mood, anxiety, and craving change when participants stop using their smartphone for 24-hours.'

\section{$\underline{\text { Procedure }}$}

'After the abstinence task was completed, participants were asked to return to the lab a fourth and final to complete the selected questionnaires.'

Should read:

'After the abstinence task was completed, participants were asked to return to the lab a fourth and final time to complete the selected questionnaires.'

\section{$\underline{\text { Figure } 1}$}

[Insert corrected Figure 1 about here. The caption text for Figure 1 should read.] 
Fig. 1. Flow diagram of procedure and participation discontinuation at each stage. Session 1 occurred a week prior to the abstinence task, session 2 occurred immediately before abstinence. The Abstinence Task lasted 24-h with session 3 taking place immediately after. Session 4 occurred a further 24-h later. This diagram also reports average Smartphone Addiction Inventory (aSPAI) scores for participants who left the study. Note, the average SPAI score for participants who discontinued at session 3 (67) was higher than the average SPAI score derived from all participants at the start of the study (55). See supplementary materials for differences between participants who completed or discontinued based on session 1 scores (Table S1).

\section{$\underline{\text { Figure } 2}$}

[Insert corrected Figure 2 about here. The caption text for Figure 2 should read.]

Fig. 2. Average scores across sessions for [A] mood, [B] anxiety, and [C] craving. Error bars represent standard error of the mean. Individual responses for participants who completed all four lab sessions appear below. These illustrate no systematic changes in mood or anxiety, but consistent changes in craving for most participants. Note that a 24-hour period of smartphone abstinence occurred between sessions 2 and 3.

\section{$\underline{\text { Results }}$}

Section 4.1 (Mood and Anxiety) should read:

'Overall, Fig. 2 suggests that mood was lower immediately before the abstinence task, but gradually increased towards the end of the study. A small reduction in anxiety is also apparent during the final session. However, ANOVAs did not reveal a significant main effect of session on $\operatorname{mood}\left[\mathrm{F}(3,105)=1.79 ; \mathrm{p}=.15 ; \mathrm{BF}_{10}=0.29\right]$ or anxiety $[\mathrm{F}$ $\left.(3,105)=1.08 ; \mathrm{p}=.36 ; \mathrm{BF}_{10}=0.13\right]$.'

Section 4.2 (Craving) should read:

'A significant main effect of session was observed on craving $[\mathrm{F}(3,105)=14.15 ; \mathrm{p}<$ $\left..0005 ; \mathrm{BF}_{10}>100\right]$. Uncorrected comparisons revealed that most sessions differed significantly from each other: session $1[\mathrm{M}=93.95 ; \mathrm{SD}=45.58]$ and session $4[\mathrm{M}=$ 66.86; $\left.\mathrm{SD}=37.06 ; \mathrm{t}(35)=4.67 ; \mathrm{p}<.0005 ; \mathrm{BF}_{10}>100\right]$; session $2[\mathrm{M}=84.80 ; \mathrm{SD}=$ 45.22 and session $3\left[\mathrm{M}=98.78 ; \mathrm{SD}=44.21 ; \mathrm{t}(40)=3.09 ; \mathrm{p}=.004 ; \mathrm{BF}_{10}=9.68\right]$; session 2 and session $4\left[\mathrm{t}(35)=3.93 ; \mathrm{p}<.0005 ; \mathrm{BF}_{10}=74.19\right]$; session 3 and session $4\left[\mathrm{t}(35)=8.16 ; \mathrm{p}<.0005 ; \mathrm{BF}_{10}>100\right]$. However no significant differences were observed between session 1 and session $2\left[\mathrm{t}(40)=1.97 ; \mathrm{p}=.06 ; \mathrm{BF}_{10}>0.97\right]$ or session 1 and session 3 [t(40) $\left.=0.91 ; \mathrm{p}=.38 ; \mathrm{BF}_{10}>0.25\right]$.'

Section 4.3 (Problematic smartphone usage) should read:

'During the first session, participants completed the problematic phone usage questionnaire (SPAI). We observed that this measure positively correlated with craving measures taken during session $1\left[\mathrm{r}(43)=0.69 ; \mathrm{p}<.0005 ; \mathrm{BF}_{10}>100\right]$, session $2\left[\mathrm{r}(39)=0.60 ; \mathrm{p}<.0005 ; \mathrm{BF}_{10}>100\right]$, session $3\left[\mathrm{r}(39)=0.62 ; \mathrm{p}<.001 ; \mathrm{BF}_{10}\right.$ 
$>100]$, and session $4\left[\mathrm{r}(34)=0.66 ; \mathrm{p}<.0005 ; \mathrm{BF}_{10}>100\right]$. Therefore, while levels of craving varied between each session, it would appear that participants who believed they used their smartphone more also reported higher levels of craving. Mood and anxiety scores were not associated with the SPAI at any time point [all p's $>0.1]$.'

\section{$\underline{\text { Discussion }}$}

The first section of the discussion should read:

'Whether or not behavioural addictions are akin to substance addictions remains a matter of considerable debate (Kardefelt-Winther et al., 2017). However, our results suggest that while smartphone abstinence can lead to craving, mood and anxiety remain unaffected. We also note that while craving did increase during the abstinence period (between sessions 2 and 3), it remained similar to levels reported a week prior to taking part (session 1). Nevertheless, while these results may indicate that smartphone users like to use their smartphones and crave them when they are unavailable, the lack of evidence for mood modification and increased anxiety suggests a key distinction between technology-related behaviours and substance abusers.'

This continues without any further correction from the sentence beginning 'Substance abusers...'

A sentence in the second paragraph of the discussion:

'However, while this may provide some evidence to confirm mood modification, our Bayes result suggests that more evidence is required to support any effect of mood before or after any period of smartphone abstinence.'

Should read:

'However, while this may provide some evidence to confirm mood modification, our Bayes result suggests that more evidence is required to support any changes to mood before or after any period of smartphone abstinence.'

A sentence in the third paragraph of the discussion:

'It is striking that drop-outs had higher SPAI scores on average'

Should read:

'It is striking that drop-outs at session 3 had slightly higher SPAI scores.'

Supplementary data

[Attach Table S1_corrected about here] 
DOI of original article: 10.1016/j.addbeh.2019.06.002

Corresponding author at: Loughborough University, Loughborough, UK. t.wilcockson@lboro.ac.uk (T.D.W.Wilcockson) 